Schultze-Krumbholz, A., Hess, M., Pfetsch, J., Scheithauer, H. (2018). Who is involved in cyberbullying? Latent class analysis of cyberbullying roles and their associations with aggression, self-esteem, and empathy. Cyberpsychology: Journal of Psychosocial Research on Cyberspace, 12(4), article 2. https://doi.org/10.5817/CP2018-4-2

\title{
Who is involved in cyberbullying? Latent class analysis of cyberbullying roles and their associations with aggression, self-esteem, and empathy
}

\author{
Anja Schultze-Krumbholz ${ }^{1,2}$, Markus Hess ${ }^{1,3}$, Jan Pfetsch², \& Herbert Scheithauer ${ }^{1}$ \\ 1 Department of Education and Psychology, Freie Universität Berlin, Germany \\ 2 Department of Educational Psychology, Technische Universität Berlin, Germany \\ ${ }^{3}$ German University of Health \& Sports, Germany
}

\begin{abstract}
The present analyses empirically explored the roles in cyberbullying by using Latent Class Analysis. Potential predictors of class membership were also examined using multinomial logistic regression analysis. Participants were 849 German students (52.7\% girls, $45.6 \%$ boys, $M_{\text {age }}=13.4$ years, $S D_{\text {age }}=1.1$ years). Observed indicators of latent class measured own involvement in cyberbullying, reactions to cyberbullying of classmates, and behavioral willingness as assistant and as defender. Indicators for the post-hoc regression analyses were proactive aggression, reactive aggression, self-esteem, cognitive, and affective empathy. Control variables were age and gender. A model with five classes was chosen. The classes were labeled prosocial defenders, communicating outsiders, aggressive defenders, bully-victims, and assistants. The results of the post-hoc regression analyses showed that students in the classes especially differed regarding types of aggression and social competencies. Based on answer patterns, cyberbullying roles beyond the bullying-triad can be found. Remarkably, three of the classes are bystanders, i.e. they are not directly involved in cyberbullying. Two of these classes showed helping behavior and made up almost two thirds of the sample. Knowledge about cyberbullying roles and their predictors is important to inform the planning and development of interventions. The results further indicate that interventions should especially take into account antisocial and passive behavioral patterns in the context of cyberbullying.
\end{abstract}

Keywords: Cyberbullying; bystanders; cyberbullying roles; aggression; empathy

\section{Introduction}

A degrading comment on a social networking site, mean insults in a classroom chat, spreading an embarrassing picture of a person to all of their friends - many forms of cyberbullying take place in a social context and aim to humiliate someone in front of others. Referring to an integrative definition, cyberbullying is "any behavior performed through electronic or digital media by individuals or groups that repeatedly communicates hostile or aggressive messages intended to inflict harm or discomfort on others" (Tokunaga, 2010, p. 278). Langos (2012) distinguishes between direct and indirect cyberbullying: Direct cyberbullying includes immediate negative communication between a cyberbully and a cybervictim, while in indirect cyberbullying the cyberbully does not direct the communication of negative content directly to a cybervictim, but to a public or semi-public audience via internet or mobile phone. In cases of indirect cyberbullying, the audience represent a necessary precondition for cyberbullying and how these persons (or bystanders) react to the incident can influence the further process of cyberbullying considerably (Pfetsch, 2016). This group of persons might behave passively, actively supporting the cybervictim or reinforcing the cyberbully and we refer to these types of behavioral patterns as cyberbullying roles, which we aim to analyze empirically in the current study. Former conceptualizations of these cyberbullying roles are mostly based on theoretical considerations or variable-centered approaches by grouping given statements 
into scales, but the current study differentiates several cyberbullying roles based on the answer patterns of the respondents. Such a person-centered approach helps to identify typical cyberbullying roles that occur in adolescents' real-life. This adds to the research literature because the used methodology of Latent Class Analysis (LCA) offers an empirically-based categorization of persons, we analyze characteristics between these different cyberbullying roles and therefore offer insights for future research and prevention practice.

Roles in bullying are an intensively researched topic in the field of offline bullying. For example, an EBSCO search with the search term "participant roles and bullying" in June 2017 resulted in 995 hits. Researchers have proposed different categorizations of the type of involvement in bullying. The most parsimonious categorization is the often used bullying triad which divides the roles into "victim", "bully", and "bystander". Since not every student is either a bully, victim, or both, and since these roles actually make up the least part of the population of children and adolescents (e.g., 8.2\% "bullies", 11.7\% "victims"; Salmivalli, Lagerspetz, Björkqvist, Österman, \& Kaukiainen, 1996), the question is warranted who the other students are, what they do and what their role is in (cyber-)bullying incidents. Offline bullying research showed that $85 \%$ of observed bullying in the classroom did not take place in a vacuum containing only the victim and the bully, but rather in the presence of witnesses or so-called bystanders (Craig, Pepler, \& Atlas, 2000). Bystanders can be involved in an active or in a passive way. In offline bullying, active bystanders can assist the bully (e.g. by holding the victim when it is being harassed), reinforce the bully (e.g. by laughing or cheering the bully on) or defend the victim (e.g. by telling the bully to stop). Passive bystanders, referred to as outsiders, do not take part in the situation in any way and, for example, pretend not to notice the bullying or remove themselves from the situation (Salmivalli et al., 1996). The most widely accepted and used typology of bullying roles is the participant roles approach by Salmivalli and colleagues (1996). Their six different categories of participants in offline bullying within the group context are: bully, victim, outsider, assistant of the bully, reinforcer of the bully, and defender of the victim. Using peer-nominations, they found that $8.2 \%$ of the participants could be assigned the role of "bully", 11.7\% "victim", 23.7\% "outsider", 6.8\% "assistant of the bully", $19.5 \%$ "reinforcer of the bully", and $17.3 \%$ the role of "defender of the victim". There also was a share of students $(12.7 \%)$ that could not be assigned a clear role in the bullying process.

The role of the bystanders is crucial in offline bullying because bystanders signalize which social behavior is acceptable within the group and their behavior defines the social norm within that specific group. Bystanders' failure to intervene in bullying situations is interpreted as approval of the behavior (Paluck \& Shepherd, 2012).

For cyberbullying, there is little empirical evidence of types of bystanders so far. In contrast to offline bullying, a search for "participant roles and cyberbullying" resulted in only 143 hits on EBSCO. However, in many of these studies, participant roles in cyberbullying are conceptualized differently than for offline bullying. Students are often categorized into perpetrators, victims, and non-involved students. Additional questions are included in the studies to identify those students who "[notice] a social situation occurring among a cyberbully and a cybervictim, and possibly other persons noticing this incident" (Pfetsch, 2016, p. 124). These are then called cyberbystanders or witnesses. Although behavioral correlates have been analyzed and compared for this group, these roles have not been extracted empirically so far, i.e. using data-driven approaches based on answer patterns. The present study is one of the first to identify cyberbullying roles with the means of LCA. We further included variables as predictors for class membership that have been investigated extensively with respect to traditional conceptualizations of bullying and cyberbullying to investigate if the relations found in previous studies remain stable applying a data-driven conceptualization of cyberbullying roles. These predictors include gender, age, aggression, self-esteem, and cognitive and affective empathy. Apart from self-esteem the other social-emotional predictors for cyberbullying involvement represent core driving forces that guide interpersonal behavior and are therefore of main importance as predictors of cyberbullying involvement. The following sections summarize previous research on the role of each predictor resulting in hypotheses for the present study.

\section{Gender and Cyberbullying Roles}

Most study results on gender in connection with cyberbullying focus on the victim and the bully role. So far they have produced mixed results (Tokunaga, 2010) with most of the reported research findings showing no gender difference and a minority suggesting female gender to be a predictor of cybervictimization. More recent metaanalyses, however, show trends into certain directions. That is, across studies, boys are more likely to be cyberbullies and girls to be cybervictims (e.g., Guo, 2016). Barlett and Coyne (2014) provide a possible explanation 
for the inconsistencies: across 109 studies from around the world, boys were cyberbullies more often overall, but the gender difference was moderated by age. Under the age of 11, more girls reported being cyberbullies, but from 11 years old onward this difference started to reverse. Moreover, a differentiated look by study region suggested that gender differences can be found in studies from the US and Asia, but not in studies from Australia or Europe (Sun, Fan, \& Du, 2016).

As with bullies and victims, studies on gender differences in cyberbystanding are also inconsistent. Some studies found boys to be cyberassistants more often and girls to be more likely to be cyberdefenders (Bastiaensens et al., 2014; Quirk \& Campbell, 2015). Others found no gender difference in negative bystander behavior such as spreading cyberbullying contents (Barlińska, Szuster, \& Winiewski, 2013) or in helping behavior (Macháčková, Dedkova, Sevcikova, \& Cerna, 2013).

The mechanisms behind gender differences in cyberbullying involvement and bystanding are manifold. In research on offline bullying, Jenkins and Nickerson (2017), for example, examined the bystander intervention model (Latané \& Darley, 1970) and found that girls are more likely than boys to perceive an incident as an emergency, which is a prerequisite for intervening in bullying. There was a surprising interaction between gender and victimization, though. Victimized girls were less likely to perceive a bullying situation as an emergency than non-victimized girls while for boys the effect was the other way around. In this same line, Bastiaensens et al. (2014) found for cyberbullying that gender differences were a function of differences in the severity perception of the incident. Both sexes are more likely to intervene in severe cyberbullying incidents. However, boys seemed to have a significantly lower severity perception, which lead the authors to conclude that lower levels in behavioral intentions for boys were due to them not perceiving the incident as severe "enough". Other research focuses on gender differences in moral values and moral disengagement (e.g., Paciello, Fida, Tramontano, Lupinetti, \& Caprara, 2008), and even gender differences in empathy (e.g., Van der Graaff et al., 2014), among others. From the presented research findings we do not assume to find consistent gender differences, but rather we expect boys to be more likely to be bullies and girls to be more likely to be victimized. Girls should also be more likely to (self-) report helping or defending behavior while boys could report being assistants more often.

\section{Age and Cyberbullying Roles}

Regarding age of cybervictims and cyberbullies, a review of existing literature suggests inconsistent results showing that some research does not find a significant association between age and cybervictimization while other studies do (Tokunaga, 2010). Using statistical indicators, meta-analyses conclude that age does not significantly predict cybervictimization (Guo, 2016; Kowalski, Guimetti, Schroeder, \& Lattanner, 2014). Tokunaga (2010) suggests that this might be attributed to the age ranges included in the studies and that, in fact, there is a curvilinear trend, i.e. cybervictimization possibly increases towards middle school and shows the highest levels during this period (e.g., Ortega, Elipe, Mora-Merchán, Calmaestra, \& Vega, 2009) and decreases again in high school (e.g., Williams \& Guerra, 2007). In contrast to cybervictimization, meta-analyses do not agree regarding a potential age trend for cyberbullying. In an analysis across 77 studies, adolescents or young adults were significantly more likely to be perpetrators of cyberbulling (Guo, 2016) whereas across 131 studies age was not a significant predictor of cyberbullying (Kowalski et al., 2014).

Regarding other cyberbullying roles, there seems to be an indication that children are more likely to intervene while adolescents stay out of cyberbullying or join in (Pfetsch, 2016). Several other studies found that within the developmental phase of adolescence (11 to 18 years old) age had no significant influence on helping a victim (Macháčková et al., 2013; Macháčková, Dedkova, Sevcikova, \& Cerna, 2018) or on exhibiting negative bystander behavior such as forwarding cyberbullying contents (Barlińska et al., 2013). Comparing 10 to 14-year-olds and 15 to 19-year-olds, Campbell et al. (2017) also found no age differences. Both age groups were most likely to either report doing nothing or helping the victim and least likely to report joining in the cyberbullying when asked to select from a list of actions they had taken when someone they know was cyberbullied. Pabian, Vandebosch, Poels, Van Cleemput, and Bastiaensens (2016) found a developmental effect: 10 to 13-year-olds, who reported being bystanders of cyberbullying at the first measurement occasion, were less empathically responsive six months later indicating a desensitization effect, which might be a mechanism behind age-related decreases in helping behavior. And Leduc, Conway, Gomez-Garibello, and Talwar (2018) found that high school students more often justified passive bystanding with deviant rules (i.e. "Anyone else would have done the same") as compared to primary 
school students. The authors suggest that with increasing age, adolescents become less likely to intervene in cyberbullying. In conclusion, victimization and bullying do not seem to show a clear linear increase with older age. Thus, based on the presented research, if at all, we expect to find age differences in helping behavior in favor of younger students.

\section{Reactive and Proactive Aggression and Cyberbullying Roles}

Aggression is any behavior, which is intended to harm another person (Anderson \& Bushman, 2002). Proactive aggression refers to negative behavior intended to obtain a resource or reach a desired goal at the cost of another person, reactive aggression occurs as an angry reaction to a frustration or provocation (Crick \& Dodge, 1996). As cyberbullying is a subtype of general aggression, it should be linked to higher reactive aggression, but especially to higher proactive aggression. Indeed, cyberbullies and cyberbully-victims were found to report higher levels of proactive aggression and reactive aggression (Ang, Huan, \& Florell, 2014; Gradinger, Strohmeier, \& Spiel, 2009; Renati, Berrone, \& Zanetti, 2012). Regarding underlying mechanisms responsible for these relations one might transfer the social deficit vs. skilled manipulator view from offline bullying to cyberbullying (Sutton, Smith, \& Swettenham, 1999). Whereas the former type is related to reactive aggression, the latter type acts more proactively. Proactive and reactive aggression is far less researched among other cyberbullying roles. However, in one study, cybervictims did not show higher proactive aggression than non-involved peers (Renati et al., 2012). Based on previous results one can assume, that cyberbullying perpetration goes along with higher reactive, but especially with higher proactive aggression. For the other cyberbullying roles the relationship is less clear, although lower levels of proactive aggression might be expected for defenders and outsiders. Regarding reactive aggression we expect, that victims and maybe also defenders might show higher levels of this form of aggression, possibly indicating use of aggression as a means of coping with frustration or as a form of impulsive defending of the victim.

\section{Cognitive and Affective Empathy and Cyberbullying Roles}

Empathy is a multifaceted phenomenon and can be defined as the ability to understand and feel the emotions of another person (Batson, 2009). While cognitive empathy is the ability to comprehend the emotional situation which is connected to perspective-taking in general as the adoption of the mental perspective of another person (Zurek \& Scheithauer, 2017) - affective empathy is the ability to vicariously experience the emotions of another person (Davis, 1994; Hoffman, 2000). Both dimensions of empathy should foster prosocial behavior and inhibit antisocial behavior, because understanding the affective situation of a victim and sharing his or her feelings creates psychological proximity and benign feelings for this person. Indeed, cognitive and affective empathy both are related negatively to offline bullying (Mitsopoulou \& Giovazolias, 2015) and cyberbullying (Del Rey et al., 2016; Pfetsch, Müller, \& Ittel, 2014; Steffgen, König, Pfetsch, \& Melzer, 2011) and positively to prosocial behavior (Eisenberg \& Miller, 1987) and defending behavior in offline bullying (Nickerson, Aloe, \& Werth, 2015; van Noorden, Haselager, Cillessen, \& Bukowski, 2015) and cyberbullying (Macháčková \& Pfetsch, 2016). Concerning other bullying roles, pro-bullies (assistants and reinforcers) in offline bullying tend to have lower affective and cognitive empathy (Gini, Albiero, Benelli, \& Altoè, 2007). Also, affective empathy reduces the probability of joining in the cyberbullying (Van Cleemput, Vandebosch, \& Pabian, 2014) and affective and cognitive empathy reduce the likelihood of forwarding a humiliating photo (Barlińska et al., 2013; Barlińska, Szuster, \& Winiewski, 2015). Further, outsiders report lower affective empathy in offline bullying (Nickerson, Mele, \& Princiotta, 2008) and cyberbullying (Van Cleemput et al., 2014). As a result of previous studies and taking into account the impact of empathy for social-emotional functioning, affective and cognitive empathy are expected to serve as protective factors against negative online behavior (cyberbullying, reinforcing, or passive cyberbystanding) and to be linked to defending cybervictims (Pfetsch, 2016).

\section{Self-Esteem and Cyberbullying Roles}

According to classic developmental theorist Erikson (1968) one of the major developmental tasks in adolescence is identity formation. This process is strongly related to the development of social relationships. Within this context, Tarrant, MacKenzie, and Hewitt (2006) found that high integration in a friendship group was indicative of high levels of self-esteem. As offline bullying and cyberbullying represent severe threats to social integration for victims it is not surprising that experiences of bullying are expected to be related to an impaired self-esteem. 
Accordingly, studies regarding bullying and self-esteem have shown that victims of bullying tend to have lower self-esteem than non-victims. Whereas the link between self-esteem and victim status in offline bullying has been established consistently (Cook, Williams, Guerra, Kim, \& Sadek, 2010; O'Moore \& Kirkham, 2001), the relation between perpetrator status and self-esteem seems to be weaker. Seals and Young (2003), for example, found no significant differences between self-esteem and groups of bullies and non-bullies.

Research on the relation between self-esteem and involvement in cyberbullying incidents has mainly focused on victims and perpetrators. Kowalski and Limber (2013), for example, found that both higher involvement in cybervictimization and cyberbullying was related to lower levels of self-esteem in a study with sixth to twelfth graders. Similar results were found by Patchin and Hinduja (2010).

Regarding the relation between self-esteem and defending behavior from bystanders in (cyber)bullying situations one can argue, that high levels of self-esteem might be associated with high confidence in social situations and thus high self-esteem in outsiders might be associated with an increase in the willingness to help victims of cyberbullying. The relation between self-esteem and prosocial or defending bystander behavior was investigated by Macháčková et al. (2013) who found no association between self-esteem and prosocial bystander behavior. This result replicated findings regarding offline bullying (Kabert, 2011). Moreover, Evans and Smokowski (2015) and Macháčková et al. (2018) even reported negative associations between self-esteem and helping behavior, indicating that those adolescent participants with lower levels of self-esteem were more willing to help victims of bullying. However, other studies presented results indicating that self-esteem was a positive predictor of defending behavior at least in offline bullying (Salmivalli, Kaukiainen, Kaistaniemi, \& Lagerspetz, 1999). One explanation for these different results might be rooted in the function of defending behavior as either maintaining actual beliefs of high self-esteem or boosting low actual feelings of self-esteem, similar to the mood maintenance and negative state relief model (see Werth \& Mayer, 2008). Based on the present evidence, the role of self-esteem in cyberbystanding is still unclear while cyberbullies and cybervictims are expected to show lower self-esteem than bystanding and defending adolescents.

\section{Aims}

To the best of our knowledge, no empirical data-driven analyses of cyberbullying roles have been published so far. Rather, until now the conventional classifications were made based on theoretical considerations, cut-off scores and other criteria or only the sub-samples of non-involved students or witnesses to cyberbullying incidents were analyzed. However, this requires theoretical assumptions about sub-groups on the side of the researchers before analysis. In contrast, LCA allows to examine the groups which can be found based on the actual data and answer patterns and can thus be used in an exploratory way. In this case, theoretical assumptions only later guide selection of the adequate model.

Therefore, in the first step (1) our aim was to empirically identify the roles present in cyberbullying using LCA and to not restrict the analysis to a sub-sample, but to include all participants allowing for combined roles. In a second step (2), we expected to find gender and age differences among the different cyberbullying roles based on previous research. Thirdly (3), we wanted to examine whether personal characteristics like levels in reactive and proactive aggression as well as cognitive and affective empathy are useful in predicting the allocation to specific cyberbullying role classes.

\section{Methods}

\section{Participants}

The present data were collected as part of a more comprehensive 3-wave longitudinal evaluation study of a cyberbullying prevention program (Schultze-Krumbholz, Zagorscak, Siebenbrock, \& Scheithauer, 2012). For the present analyses, only the data from the first measurement occasion in January 2011 (baseline assessment) were used to prevent distortions caused by intervention effects. In total, 897 students from five schools in a major German city participated in this measurement occasion. Of these, 849 students (missing rate $=5.4 \%$ ) provided complete data on all the indicators included in the first step of the analyses, the LCA. Additional incompleteness of data can be found for the post-hoc analyses (sample size for post-hoc analyses $n=834$ ). Of the students included 
in the LCA $52.7 \%$ were girls, $45.6 \%$ boys and $1.8 \%$ did not indicate their gender. Participants attended Grades 7-10 and were aged between 11 and 17 years $\left(M_{\text {age }}=13.44, S D_{\text {age }}=1.06\right)$. Of the participants, $21.6 \%$ attended general high school while the majority (78.4\%) of students were recruited from college preparatory high school.

\section{Procedure}

Students' active consent was collected as well as parents' active consent if the students were 14 years old or younger. Data were collected during regular school lessons using standardized self-report paper-and-pencil questionnaires. A member of the research team was present during data assessment in each class, was available for questions and collected the questionnaires. All participants were guaranteed anonymity and voluntariness. The procedure was approved by the responsible school administration of the federate state, where data collection took place.

\section{Measures}

A multitude of indicators, predictors, and outcomes of cyberbullying and cybervictimization were assessed in the overall study using a questionnaire. Observed indicators of latent classes for the present analyses referred to own involvement in cyberbullying, self-ratings of possible reactions to witnessing cyberbullying, behavioral willingness as an assistant, and behavioral willingness as a defender to allow a better systematization of the broad range of social behavioral patterns in cyberbullying. Independent variables for the post-hoc multinomial regression analysis were age, gender, proactive aggression, reactive aggression, self-esteem, cognitive, and affective empathy.

\section{Indicators for latent class analysis.}

Cyberbullying and cybervictimization. Involvement in cyberbullying was assessed with the German version of the European Cyberbullying Intervention Project Questionnaire (ECIPQ, Del Rey et al., 2015; Schultze-Krumbholz, Siebenbrock, Zagorscak, \& Scheithauer, 2011). Using a 5-point Likert answer scale $(1=$ no to $5=$ yes, more than once a week) the instrument originally presented twelve behavioral items for each the perpetration of and victimization through cyberbullying (e.g. "I said nasty things to someone or called them names using texts or online messages" and "Someone said nasty things to me or called me names using texts or online messages", respectively). Due to ambiguity, one item referring to attacks in online games was removed from each scale resulting in eleven items per scale (Cronbach's $a=.88$ and .71, respectively) (see also Del Rey et al., 2015). The scores were summed across the respective continuous eleven indicators and dichotomized into a variable for cyberbullying and one for cybervictimization with scores smaller than or equal to 2 being recoded into 0 (no or only once or twice) and scores greater than 2 into 1 (once or twice a month or more often).

Bystanders' behavior in cyberbullying. To assess the behavior students would show when gaining knowledge of a cyberbullying incident they were asked "Imagine, one of your classmates is being bullied through the Internet or by cell phone and suffers from it. How would you act?" and were presented with a list of eleven possible actions to choose from: tell class/school mates, tell a teacher, tell parents, tell a friend, do nothing, turn away as not to notice it, tell the bully to stop (confront), activate a group of people to help the victim, comfort the victim and help to think of what to do, make fun of the material and the victim, and pass on the material to friends to make fun of the victim. Participants were explicitly allowed to choose more than one option. Answers were coded 0 and $1(0=$ answer not chosen, 1 = answer chosen). All of the items were included in the analysis as dichotomous single item indicators.

Willingness to participate in cyberbullying. In the context of another research question (Schultze-Krumbholz, Zagorscak, Wölfer, \& Scheithauer, 2014), four items on behavioral willingness were developed based on Gibbons, Gerrard, Blanton, and Russell (1998). One of these items referred to willingness to assist in sending a threatening message or post a humiliating video/photo of someone the peer group does not like and one asked about willingness to defend an unpopular person who is being threatened, insulted or made fun of in an online group. Both items were included in the analyses as single items and the seven-point answer scale $(1=$ not at all likely to 7 = very likely) was dichotomized into 0 (not likely) and 1 (likely) with the answer categories 1 to 4 being recoded as not likely and the categories 5 to 7 as likely to assist or defend, respectively. 
Independent variables for post-hoc multinomial regression analysis.

Proactive and reactive aggression. Adapted versions of the Instrumental Overt Aggression Scale and the Reactive Overt Aggression Scale (Little, Jones, Henrich, \& Hawley, 2003), each containing an additional item for the cyber context (Gradinger et al., 2009), were used to assess two different types of aggression on a 4-point Likert scale (1 $=$ not true to $4=$ completely true) Cronbach's a was .91 for proactive aggression and .86 for reactive aggression, respectively. Examples are "To get what I want, I often hurt others." (proactive) and "When I'm hurt by someone, I often fight back." (reactive).

Self-esteem. An adapted 8-item German version (Fend, Helmke, \& Richter, 1984) of the Rosenberg Self-Esteem scale (Rosenberg, 1965) was used to assess global self-esteem on a 4-point answer scale $(1=$ not true to $4=$ completely true), Cronbach's $a=.87$. Negatively worded items were reverse coded. An example item is "On the whole, I am satisfied with myself.".

Cognitive empathy. Participants rated their own skills in cognitive empathy on the 8-item perspective-taking subscale of the Interpersonal Reactivity Index (Davis, 1980; German translation: Lamsfuss, Silbereisen, \& Boehnke, 1992) using a 5-point answer scale ( 1 never true to 5 almost always true), Cronbach's a $=.85$. An example is "I sometimes try to understand my friends better by imagining how things look from their perspective".

Affective empathy. Adolescents' tendency to show affective empathy was assessed by presenting them a stimulus situation from the Sympathy Reactivity Questionnaire (Volland, Ulich, Kienbaum, \& Hölzle, 2008), which we adapted for the cyber context: "Imagine you are on Facebook and come across a hate group against a person where others post mean and insulting comments. You find out that the person knows about this group. What would you think?". After reading this stimulus situation, adolescents answered questions about how they would react emotionally on a 6-point scale (1 not at all true to 6 completely true), e.g. "Because I found out about this group, I am sad myself.". The original seven items were assessed, but only four (being touched by the situation, caring about whether the person is doing better soon, being sad oneself about the situation and worrying about the person) were included into scale computation to include only the affective components in the analyses, Cronbach's $a=.79$. Negatively worded items were reverse coded.

\section{Data Analysis}

The present analyses were conducted in two steps. To answer the first research question about roles based on self-reported behavioral intentions in cyberbullying situations a LCA was conducted using Mplus 7 statistical package (Muthén \& Muthén, 1998-2012). This is a person-centered approach that analyses answer patterns and assigns persons with similar patterns to groups (classes) while keeping the distinction between groups high. Since LCA is based on item response theory, results are not deterministic, but instead probabilistic, i.e. a person is assigned to a specific class based on probabilities (Gollwitzer, 2007). Successive LCA models with ascending number of classes were computed and then model selection was determined by evaluating underlying statistical evidence in cooperation with theoretical considerations (Nylund, Bellmore, Nishina, \& Graham, 2007). Statistical indicators used to assess model fit and to determine an adequate model were log-likelihood value, Akaike information criterion (AIC), Bayesian information criterion (BIC), the sample size-adjusted Bayesian criterion (aBIC), Bootstrap Likelihood Ratio Test (BLRT). Furthermore, the entropy and posterior probabilities for each model were examined.

In the present analysis, the class with the highest probability was assigned to each student and was subsequently used as the dependent variable in a multinomial logistic regression analysis with proactive aggression, reactive aggression, self-esteem, cognitive empathy, and affective empathy in order to compare the extracted latent classes. In addition, we controlled for age and gender. A set of three regression models was computed, each time including an additional block of predictors. Block 1 consisted of age and gender, block 2 included proactive and reactive aggression and self-esteem, and block 3 was made up of cognitive and affective empathy. The multinomial logistic regression analyses were computed in SPSS 24 and were used in order to make person-centered interpretations. 


\section{Results}

The results are presented in two parts. First, results of the LCA are presented, showing the structure, number and profiles of classes. Second, three multinomial logistic regression models, successively including an additional block of predictors, are presented for latent class as dependent variable.

\section{Model Selection and Latent Classes}

Details on fit indices for models with increasing number of latent classes are provided in Table 1. As can be seen from the statistical information, no one specific model clearly emerged as the best model. The 3-class solution shows the best BIC and the highest entropy of the multi-class models, while the 5-class solution shows the best AIC, adjusted BIC and loglikelihood. Even though the 6-class solution has better fit than the 5-class solution on AIC and log-likelihood, the statistics program was not able to replicate the model sufficiently often indicating a lack of stability and too many parameters. There seems to be disagreement as to which fit statistic indicates the best model fit. Studies have shown entropy to perform poorly (e.g. Tein, Coxe, \& Cham, 2013) and disagree on whether BIC or adjusted BIC outperforms the other (e.g. Nylund, Asparouhov, \& Muthén, 2007; Tein et al., 2013; Tofighi \& Enders, 2007). Based on our aim to disentangle and distinguish the bystanders of cyberbullying as well as research results from offline bullying reporting six groups (Participant Role approach, Salmivalli et al., 1996) and the presence of distinct interpretability, we chose the 5-class solution to examine different behavioral patterns in cyberbullying incidents as this seemed the most interesting to us for cyberbullying research. Average posterior probabilities for the membership in each latent class were acceptable (.76) to good (>.80).

Table 1. Latent Class Analyses Fit Indices $(N=849)$.

\begin{tabular}{|c|c|c|c|c|c|c|}
\hline No. of classes & AIC & BIC & $\mathrm{aBIC}$ & Log-likelihood & $\begin{array}{c}\text { BLRT } \\
\text { p value }\end{array}$ & Entropy \\
\hline 1 class & 11952.512 & 12023.673 & 11976.038 & -5961.256 & $n / a^{1}$ & 1.000 \\
\hline 2 classes & 11492.287 & 11639.352 & 11540.906 & -5715.143 & $<0.001$ & 0.701 \\
\hline 3 classes & 11412.267 & 11635.238 & 11485.980 & -5659.133 & $<0.001$ & 0.739 \\
\hline 4 classes & 11361.171 & 11660.047 & 11459.978 & -5617.586 & $<0.001$ & 0.637 \\
\hline 5 classes & 11324.219 & 11698.999 & 11448.119 & -5583.109 & $<0.001$ & 0.687 \\
\hline 6 classes & 11307.058 & 11757.744 & 11456.052 & -5558.529 & $<0.001$ & 0.683 \\
\hline
\end{tabular}

Note: AIC = Akaike Information Criteria; BIC = Bayesian Information Criteria; aBIC = Adjusted BIC; BLRT = Bootstrapped Likelihood Ratio Test. Bolded classes indicate the best-fitting model. The Model with 6 classes was not stable: Manual replications of this model repeatedly produced different results from the first solution.

${ }^{1}$ BLRT not available for one-class model.

The item probability distribution for each latent class of cyberbullying role is shown in Figure 1 providing a profile of answers for each class. We labeled the extracted classes as follows: communicating outsiders (class $1 ; 28.4 \%, n=$ 241), aggressive defenders (class 2; 9.5\%, $n=81$ ), bully-victims (class 3; 7.1\%, $n=60$ ), "prosocial" defenders (class 4; $52.2 \%, n=443$ ), and assistants (class $5 ; 2.8 \%, n=24$ ). Communicating outsiders, hereafter simply referred to as outsiders, show low probabilities of endorsing any involvement type in cyberbullying (i.e. being an assistant, defender, bully, or victim). They tend to tell peers and their parents, but otherwise hardly become active when gaining knowledge about an incident. Outsiders make up almost one third of the participants of this study. The class of aggressive defenders also had a comparably high probability of endorsing the items about telling peers and are less likely to report telling adults about cyberbullying incidents. Instead, they are likely to endorse "confront bully", "activate others" and "comfort". They are likely to endorse the defender scenario, but are also likely to endorse the assistant scenario and to report cyberbullying victimization as well as perpetration to nearly the same degree as the bully-victims, which is the reason why we named this group "aggressive". About every tenth participant of our sample is part of this group. The class of bully-victims comprises adolescents who report cyberbullying perpetration and victimization as well as a tendency to endorse the assistant scenario while not being likely to report willingness to defend. Bully-victims tell peers about cyberbullying incidents and are more likely to endorse antisocial behaviors like making fun of the victim and passing messages or other material on to others. Members in the biggest class with more than half of study participants in the group of prosocial defenders have the highest probability of telling adults about cyberbullying and comforting the victim. They do not report cyberbullying perpetration or victimization and do not endorse the assistant scenario. The smallest group of 
assistants does not intervene and is likely to be willing to join in cyberbullying (assistant scenario). However, participants of this group did not endorse typical assistant behavior like making fun of the material or passing on the material.
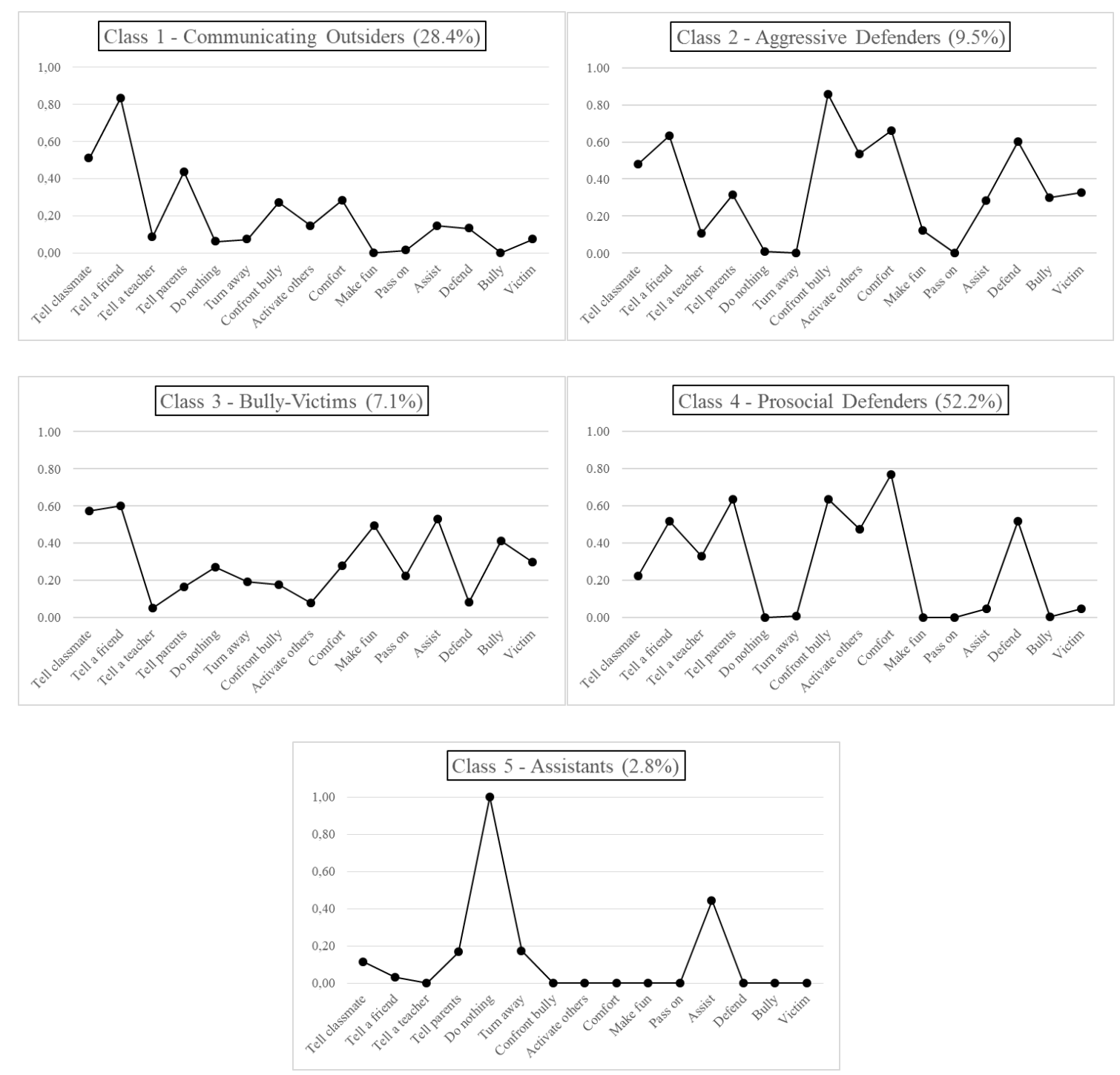

Figure 1. Item probability profile plots for each class of cyberbullying roles $(N=849)$.

\section{Predictors of Class Membership}

We used a stepwise computation of models in order to investigate the contribution of blocks of variables in explaining differences in class membership. Mean scores of the predictors can be found in Table 2 . The results of the three stepwise multinomial logistic regressions are summarized in Table 3. The coefficients associated with each variable represent odds ratios $(O R)$ of a particular demographic characteristic or individual characteristic in the groups involved in cyberbullying relative to those who are not involved, the so-called outsiders.

Model 1 included age and gender. Results show, that older age increased the probability of being a bully-victim $(O R=1.44)$ and younger age was related to being a prosocial defender $(O R=0.79)$ as compared to being an outsider. Male gender was related to being a bully-victim $(O R=0.29)$ or an assistant $(O R=0.03)$ in cyberbullying others. However, in models 2 and 3, where additional variables were included, age and gender effects related to bully-victims vanished. In Model 3 a gender effect emerged indicating that male gender has predictive value for being a prosocial defender $(O R=0.60)$. 
Table 2. Mean Scores of Predictors by Class.

\begin{tabular}{lccccccc}
\hline & $\begin{array}{c}\text { Bully- } \\
\text { Victims } \\
(n=60)\end{array}$ & $\begin{array}{c}\text { Assistants } \\
(n=24)\end{array}$ & $\begin{array}{c}\text { Class } \\
\text { Defenders } \\
(n=81)\end{array}$ & $\begin{array}{c}\text { Pefenders } \\
(n=443)\end{array}$ & $\begin{array}{c}\text { Communicating } \\
\text { Outsiders } \\
(n=241)\end{array}$ \\
& $M(S D)$ & $M(S D)$ & $M(S D)$ & $M(S D)$ & $M(S D)$ & $F(4 ; 703)$ & $\eta^{2}$ \\
\hline Age & $14.00(1.30)$ & $13.42(0.93)$ & $13.58(1.18)$ & $13.28(1.02)$ & $13.54(0.99)$ & $7.62^{* * *}$ & .04 \\
Proactive Aggression & $1.86(0.74)$ & $1.50(0.75)$ & $1.48(0.58)$ & $1.13(0.27)$ & $1.26(0.37)$ & $43.66^{* * *}$ & .20 \\
Reactive Aggression & $2.41(0.66)$ & $2.21(0.62)$ & $2.02(0.65)$ & $1.49(0.49)$ & $1.68(0.52)$ & $48.12^{* * *}$ & .21 \\
Self-esteem & $3.23(0.59)$ & $3.05(0.70)$ & $3.01(0.66)$ & $3.14(0.57)$ & $3.09(0.56)$ & 1.38 & .01 \\
Cognitive empathy & $2.71(0.76)$ & $2.58(0.79)$ & $3.16(0.70)$ & $3.38(0.63)$ & $3.10(0.59)$ & $20.69 * * *$ & .10 \\
Affective Empathy & $2.59(1.09)$ & $2.51(1.30)$ & $3.49(1.12)$ & $3.99(1.06)$ & $3.45(1.00)$ & $29.91 * * *$ & .14 \\
\hline
\end{tabular}

Note: ${ }^{* \star} p<.001$.

Table 3. Regression Coefficients and Odds Ratios (OR) for the 5-Class Model with Proactive Aggression, Reactive Aggression, SelfEsteem, Cognitive and Affective Empathy as Predictors of Class Membership and Age and Gender as Control Variables Using the Outsider Class as the Comparison Group.

\begin{tabular}{|c|c|c|c|c|c|c|c|c|c|c|}
\hline \multirow{2}{*}{ Class } & & \multicolumn{3}{|c|}{ Model 1} & \multicolumn{3}{|c|}{ Model 2} & \multicolumn{3}{|c|}{ Model 3} \\
\hline & & $B(S E)$ & Wald & $O R$ & $B(S E)$ & Wald & $O R$ & $B(S E)$ & Wald & $O R$ \\
\hline \multirow{8}{*}{$\begin{array}{l}\text { Bully- } \\
\text { Victims }\end{array}$} & Constant & $-5.91(1.80)$ & $10.80 * \star$ & & $-8.18(2.44)$ & $11.21 *$ & & $-5.63(2.59)$ & $4.72^{\star}$ & \\
\hline & Age & $0.37(0.13)$ & $8.04 * *$ & 1.4 & $0.24(0.16)$ & 2.26 & 1.26 & $0.28(0.16)$ & 2.88 & 1.3 \\
\hline & Gender & $-1.26(0.32)$ & $15.04 * *$ & 0.2 & $-0.42(0.40)$ & 1.10 & 0.66 & $-0.06(0.42)$ & 0.02 & 0.9 \\
\hline & Proactive & & & & $0.84(0.37)$ & $5.26 *$ & 2.32 & $0.80(0.38)$ & $4.43^{*}$ & 2.2 \\
\hline & Reactive Aggr. & & & & $1.02(0.36)$ & $8.09 * *$ & 2.77 & $1.02(0.38)$ & $7.35^{*}$ & 2.7 \\
\hline & Self-Esteem & & & & $0.12(0.32)$ & 0.15 & 1.13 & $0.10(0.33)$ & 0.10 & 1.1 \\
\hline & Cog. Empathy & & & & & & & $-0.61(0.29)$ & $4.45^{*}$ & 0.5 \\
\hline & Aff. Empathy & & & & & & & $-0.45(0.19)$ & $5.50 *$ & 0.6 \\
\hline \multirow{8}{*}{ Assistants } & Constant & $-0.30(2.79)$ & 0.01 & & $0.14(3.48)$ & 0.00 & & $3.02(3.82)$ & 0.62 & \\
\hline & Age & $-0.10(0.21)$ & 0.21 & 0.9 & $-0.17(0.24)$ & 0.47 & 0.85 & $-0.13(0.26)$ & 0.26 & 0.8 \\
\hline & Gender & $-2.23(0.63)$ & $12.45^{\star *}$ & 0.0 & $-2.18(0.79)$ & $7.55^{* *}$ & 0.11 & $-1.70(0.81)$ & $4.41 *$ & 0.1 \\
\hline & Proactive & & & & $0.09(0.53)$ & 0.03 & 1.09 & $0.03(0.55)$ & 0.00 & 1.0 \\
\hline & Reactive Aggr. & & & & $1.04(0.51)$ & $4.23^{*}$ & 2.83 & $1.00(0.51)$ & $3.85^{\star}$ & 2.7 \\
\hline & Self-Esteem & & & & $-0.59(0.39)$ & 2.26 & 0.56 & $-0.55(0.40)$ & 1.92 & 0.5 \\
\hline & Cog. Empathy & & & & & & & $-0.57(0.39)$ & 2.17 & 0.5 \\
\hline & Aff. Empathy & & & & & & & $-0.61(0.28)$ & $4.69 *$ & 0.5 \\
\hline \multirow{8}{*}{$\begin{array}{l}\text { Aggressive } \\
\text { Defenders }\end{array}$} & Constant & $-1.43(1.62)$ & 0.78 & & $-1.59(2.08)$ & 0.58 & & $-2.90(2.24)$ & 1.68 & \\
\hline & Age & $0.04(0.12)$ & 0.13 & 1.0 & $-0.06(0.14)$ & 0.21 & 0.94 & $-0.08(0.14)$ & 0.28 & 0.9 \\
\hline & Gender & $-0.41(0.26)$ & 2.48 & 0.6 & $0.06(0.33)$ & 0.03 & 1.06 & $-0.10(0.34)$ & 0.08 & 0.9 \\
\hline & Proactive & & & & $0.40(0.36)$ & 1.23 & 1.49 & $0.37(0.37)$ & 1.02 & 1.4 \\
\hline & Reactive Aggr. & & & & $0.79(0.31)$ & $6.36^{*}$ & 1.21 & $0.90(0.32)$ & $7.77^{\star}$ & 2.4 \\
\hline & Self-Esteem & & & & $-0.26(0.25)$ & 1.09 & 0.77 & $-0.26(0.25)$ & 1.08 & 0.7 \\
\hline & Cog. Empathy & & & & & & & $0.32(0.24)$ & 1.72 & 1.3 \\
\hline & Aff. Empathy & & & & & & & $0.13(0.15)$ & 0.73 & 1.1 \\
\hline \multirow{8}{*}{$\begin{array}{l}\text { Prosocial } \\
\text { Defenders }\end{array}$} & Constant & $3.77(1.06)$ & $12.71 * \star$ & & $5.55(1.33)$ & $17.36^{\star}$ & & $2.57(1.48)$ & 3.01 & \\
\hline & Age & $-0.24(0.08)$ & $9.39 * *$ & 0.7 & $-0.23(0.09)$ & $7.20 * *$ & 0.80 & $-0.24(0.09)$ & $7.14 *$ & 0.7 \\
\hline & Gender & $0.09(0.17)$ & 0.30 & 1.1 & $-0.19(0.20)$ & 0.85 & 0.83 & $-0.52(0.22)$ & $5.64^{*}$ & 0.6 \\
\hline & Proactive & & & & $-1.07(0.37)$ & $8.60 * *$ & 0.32 & $-0.88(0.37)$ & $5.62 *$ & 0.4 \\
\hline & Reactive Aggr. & & & & $-0.51(0.22)$ & $5.24 *$ & 0.60 & $-0.38(0.23)$ & 2.75 & 0.6 \\
\hline & Self-Esteem & & & & $0.08(0.08)$ & 0.23 & 1.08 & $0.05(0.17)$ & 0.10 & 1.0 \\
\hline & Cog. Empathy & & & & & & & $0.54(0.16)$ & $11.98 * \star$ & 1.7 \\
\hline & Aff. Empathy & & & & & & & $0.33(0.10)$ & 12.21 ** & 1.3 \\
\hline \multicolumn{2}{|c|}{ Nagelkerke's R } & .089 & & & .260 & & & .348 & & \\
\hline \multicolumn{2}{|l|}{$\chi^{2}(d f)$} & $70.45(8)$ & & & $192.43(20)$ & & & $270.11(28)$ & & \\
\hline
\end{tabular}

Note: Reference category is: communicating outsiders, gender: $0=$ female, $1=$ male, ${ }^{\star} p<.05,{ }^{\star \star} p<.01,{ }^{* \star *} p<.001$. 
Model 2, where proactive aggression, reactive aggression and self-esteem were added, and model 3, with cognitive and affective empathy as additional variables, did not differ substantially. Model 3 included all variables for the present study and results can be summarized as follows: Higher levels of reactive $(O R=2.77)$ and proactive aggression $(O R=2.23)$ increased the probability of individuals to be categorized as bully-victims compared to outsiders. Interestingly, only reactive aggression had a significant predictive value for adolescents to be categorized as assistants $(O R=2.71)$ and aggressive defenders $(O R=2.45)$. Lower levels of proactive aggression increased the probability of being categorized as a prosocial defender $(O R=0.42)$. In contrast to what could be expected, self-esteem had no predictive value at all in the present sample.

Regarding the contribution of cognitive and affective empathy a mixed pattern emerged. As could be expected, high levels of affective empathy $(O R=1.34)$ and cognitive empathy $(O R=1.72)$ were associated with status as prosocial defender compared to outsiders. In contrast, low levels of cognitive empathy only predicted membership in the bully-victim class $(O R=0.55)$. Low scores on affective empathy were associated with being a bully-victim (OR $=0.64)$ and an assistant $(O R=0.54)$. Neither cognitive nor affective empathy proved to be relevant to separate aggressive defenders from outsiders.

\section{Discussion}

Despite the growing number of studies dealing with participant roles in cyberbullying contexts there is a lack of data-driven research defining these roles. Therefore, the first aim of the present study was to identify cyberbullying roles empirically based on participants' answer patterns including answers to behavior-based questions (cyberbullying, cybervictimization) and hypothetical scenarios (bystander behavior) using LCA. In addition, after identifying these participant roles in cyberbullying the second goal of the study was to learn more about individual factors derived from previous research that help to predict membership in one of the cyberbullying classes (aggression, self-esteem, and cognitive and affective empathy).

Regarding the first research question, we used a data-driven and person-oriented approach by implementing LCA. After careful considerations about the trade-off between empirical and content-wise interpretation of the data we favored a 5-class solution. This 5-class model yielded one group of bully-victims, a very small group of assistants, a group of outsiders and two groups of defenders, one with a more prosocial profile, the other with a more aggressive profile.

As an instrument to detect "subtypes of individuals that exhibit similar patterns of individual characteristics" (Collins \& Lanza, 2010, p. 8) within data, LCA is usually used as an exploratory method (Hoijtink, 2001) as we have done, although confirmatory approaches have also been developed in the past years. Based on statistical parameters the 5-class solution was able to differentiate satisfactorily between the classes, although we had to acquiesce with a decrease in entropy. Content-wise, the resulting patterns were easy to interpret, and showed high levels of coherence within and differentiation between the different classes.

However, the statistical evidence was not as clear as hoped: no one latent class model was clearly the most fitting. A possible 3-class solution yielded a defender class (70.8\%), an outsider class (21.1\%) and a bully-victim class (8.1\%). However, this 3-class solution was not able to inform about more fine-grained differences between patterns of participating roles as the 5-class solution did. It is not unusual for LCA to produce inconclusive results making it necessary to decide for a solution based on theoretical considerations. LCA looks for similar patterns and groups individuals according to their closeness to these patterns. However, within the different groups (classes), differences between individuals might still be comparatively large, especially if the classes consist of only few individuals. Opportunity to differ from each other is increased with a growing number of indicators. In our case, fifteen indicators might have been too large a number to produce classes where members are very closely alike to each other.

Like in other studies (e.g., Gradinger et al., 2009), bystanders (i.e. defenders and outsiders) were the largest group as compared to adolescents who were involved in cyberbullying. The high prevalence of defenders could be influenced by a social desirability bias (Paulhus, 1984) and by the fact that participants mainly answered question about hypothetical scenarios and not real life experiences. The scenarios referred to a classmate, but did not indicate the type of relationship with this classmate. If students imagined a classmate they liked, they might also 
have answered with prosocial reactions more often. Regarding social desirability, a study concerning offline bullying found only small to not significant relations between behavioral intentions to support offline victims and a social desirability scale among primary and secondary school students (Rigby \& Johnson, 2006). However, a study on the use of hypothetical scenarios indicates that people might answer more socially desirable when no costs are associated with the choice (Norwood \& Lusk, 2011). It remains to be investigated whether this is applicable for the context of the present study.

The present result of a mixed perpetrator and victim class is in line with previous findings, which we conducted on the basis of the separate cyberbullying and victimization items and using additional participants from other countries (Schultze-Krumbholz et al., 2014). Not surprisingly, this group is not likely to be very supportive towards targets of cyberbullying, although based on empathy theory one might expect victims to show more empathy towards other victims. However, the significant predictors in our analyses indicate that this group is characterized by lower levels of social competences and higher levels of aggression. These results mirror previous findings indicating lower levels of affective empathy among cyberbully-victims (Pfetsch, Müller, \& Ittel, 2014; Steffgen et al., 2011) as well as higher levels of proactive and reactive aggression (e.g., Gradinger et al., 2009; Renati et al., 2012). With regard to the present results one might argue that the group of cyberbully-victims is best characterized by applying a social deficit hypothesis as formulated by Sutton and colleagues (1999) whereas the skilled manipulators represent no distinct group in the cyber-context. One reason for this might be that perpetrators aiming at hurting others often will not get immediate and/ or satisfying "rewards" online in contrast to offline contexts and therefore might prefer offline bullying actions. Age and gender only were significant predictors when no other predictors were included in the analyses. Thus, age and gender do not predict allocation to the bullyvictim class over and above aggression and lack of social competences. Barlińska et al. (2013) found that cyberbullies are more likely to show negative bystander behavior while there was no significant relation between victimization and negative bystander behavior. Our bully-victim class seems to show more characteristics of bullying while victim characteristics do not seem to be able to suppress antisocial characteristics. Telling friends or classmates/schoolmates about the cyberbullying incident cannot necessarily be interpreted as supportive behavior in our study, because we did not specify what is being communicated. Adolescents might tell peers about cyberbullying as a sort of sharing, making fun of or passing on an incident even though we assessed this specifically with additional items.

The same might apply to the outsider class. The term outsider might be ambiguous since in our study it did not refer to students who do not notice cyberbullying, but rather to those who are not involved in cyberbullying in any of the classic roles. They actually do not stay completely passive, because they talk to friends and parents, but hardly become active in other ways. Thus, this group might be comparable to passive bystander groups of other studies (e.g., Macháčková et al., 2018; Olenik-Shemesh, Heiman, \& Eden, 2017).

Our results deviated from other studies in that these studies found the majority of cyberbystanders to remain passive; estimates range from around $50 \%$ to over $90 \%$ of witnesses who ignored cyberbullying at some point (Lenhart et al., 2011). These studies often assessed specific situations (as compared to hypothetical in our study) and online intervention of bystanders. In our study, students could also indicate offline intervention or offline support, which was not assessed in those studies. The hypothetical situation on the one hand and the possibility of offline support on the other hand might be reasons why levels of outsiders are rather low in our study in comparison (28.4\%).

It is a very positive result that about two thirds of the adolescents in our sample were identified as defenders, although they were not completely prosocial in nature. Interestingly, these defenders could further be differentiated into rather aggressive defenders and prosocial defenders. This difference is also supported by the predictors in the logistic regression analysis: membership in the class of aggressive defenders was predicted by higher levels of reactive aggression as expected (as compared to outsiders) while membership in the class of prosocial defenders is predicted by lower levels of proactive aggression, also in line with our expectation. The prosocial aspect of the prosocial defenders is emphasized by the significant predictors of cognitive and affective empathy for membership in this class. Further, it seems that these prosocial defenders make use of a variety of courageous and confronting (the bully) as well as more defensive strategies (telling adults) to intervene in cyberbullying situations. Their other-oriented cognitive and affective involvement motivates them to help in an appropriate way fitting the current situation. 
In contrast, the present results indicate that actions of aggressive defenders in cyberbullying situations might be rather maladaptive, due to several reasons. First, they show higher levels of reactive aggression suggesting that they might be prone to react impulsively when confronted with cyberbullying situations. Second, as results of the LCA indicate, these adolescents are themselves more often involved as bullies and/ or victims in the cyber-context than their prosocial counterparts. And third, these adolescent do not show outstanding levels of social-emotional competencies as compared to communicating outsiders. However, as the present results are cross-sectional in nature, it is rather difficult to delineate the actual mechanisms behind these findings.

At least three mechanisms might be proposed to better understand the characteristics of aggressive defenders: First, one might speculate that insufficient attempts to defend others might result in own victimization. Second, one might argue that own experiences of victimization are the driving force behind aggressive defending actions that are not easy to delineate from bullying. Third, low social-emotional competencies paired with high levels of impulsivity and reactive aggression might produce aggressive defending and make it prone to cause more interpersonal trouble.

Allocation to the prosocial defenders class was also predicted by younger age, which is in line with our expectations and the findings of Pabian et al. (2016) that a desensitization effect might take place with increasing age. Surprisingly, not female but male gender predicted being categorized a prosocial defender (as compared to the outsiders), which stands in contrast to what we expected as well as to previous research like the study of Bastiaensens et al. (2014) who found in an experimental setting that female adolescents were more likely to defend the victim.

The class of assistants had a rather simple profile. It is a comparably small group, but very outstanding in their pattern. They were $100 \%$ likely to report doing nothing in cyberbullying situations and the only other peak was in assisting in cyberbullying. Their scores in reactive aggression are comparable to those of the bully-victims and a lack of empathy was also a significant predictor for being a member of the assistant class, similar to the bullyvictims. Interestingly, they did not report cyberbullying perpetration. The similarities to the bully-victims might, however, indicate that assistants run a risk of becoming cyberbullies (and cybervictims) in the future. Different from the bully-victims where age and gender effects disappeared after including aggression and social competences, being male was a significant predictor of allocation to the assistant class indicating that this might be a very specific, albeit small, risk group.

As the previous discussion of the participant roles in cyberbullying suggested, the method of LCA produces classes that are highly distinct from each other. The results of this cross-sectional analysis might also have implied that the roles are stable roles. However, previous research found that cyberbullying roles are neither clearly distinct from each other nor stable over time. According to a study by DeSmet et al. (2014) bystander roles are not stable across contexts, but rather the bystander behavior depends more on the context of the single incident and characteristics of the involved parties (i.e. the target is a friend, the cyberbully is unpopular, the incident is perceived as unfair, etc.) than on a supposedly trait-like general role in cyberbullying incidents. The present results do not depict these influences. Also, Pfetsch, Müller, Walk, and Ittel (2014) found that cyberbullying roles are not necessarily mutually exclusive. In their sample, only $40 \%$ of the 428 adolescents could be assigned one role while the rest had two to four roles within one single incident. Since participants were allowed to choose multiple answers and we were able to see that, for example, bully-victims did to some degree endorse prosocial items like comforting, we may have succeeded in depicting overlap of roles in our results.

\section{Limitations, Implications, and Future Directions}

Some limitations of our study should be mentioned. The instructions we used were very general and undifferentiated and the responses of the participants concerning bystander behavior were related to hypothetical scenarios. A further limitation is that the actor in the scenario was a classmate. Previous studies have shown several contextual factors to influence behavioral intentions in cyberbystanders. For example, the severity of the incident seems to be of great importance as well as the presence and identity of other bystanders (Bastiaensens et al., 2014). Future studies should therefore use more specific instructions that clarify the hypothetical situation and do not assume cyberbullying roles to be traits of the study participants, but rather allow for them to be states that change across contexts. At least the severity of the incident should be specified, because 
leaving this aspect open to interpretation likely leads to a greater variance in participants' answers (cf. Hollá, Fenyvesiová, \& Hanuliaková, 2017; Palladino et al., 2017).

Another limitation is that the choice of a latent class model was not a clear and indisputable choice. There was a contesting model with three classes, which showed the best fit on two indicators, while the five-class model fared better on three other indicators. In the end, we made a decision based on content-related considerations and the assumption that more knowledge and insight could be gained from the five-class model. The rationale for our choice has been explained in detail in the previous sections.

The present study shows that based on answer patterns, cyberbullying roles beyond the bullying-triad can be found. Remarkably, three of the classes are bystanders, i.e. they are not directly involved in cyberbullying. Two of these classes showed helping behavior (although in different ways) and made up almost two thirds of the sample. The results of the post-hoc regression analyses showed that students in the classes especially differed regarding types and levels of aggression and social competencies. Some age and gender differences were also found, although not for every cyberbullying role.

The presented results presumably have implications for the development of intervention measures and preventive interventions, respectively. We assume that differences in cyberbullying roles, associated with different social and psychological characteristics in the adolescents involved, might demand different types of treatment and/or preventive interventions. Interventions, preventive interventions respectively, not addressing differences with regard to cyberbullying roles and associated characteristics may result in a lower impact or even no change in the negative behavior at all. Thus, it can be assumed that interventions tailored specifically to the participant's cyberbullying role and/or to associated characteristics, may be more efficacious (e.g., DiFranzo, Taylor, Kazerooni, Wherry, \& Bazarova, 2018; for an example of a "taylored" preventive intervention for offline bullying roles see Evers, Prochaska, Van Marter, Johnson, \& Prochaska, 2007). In the present study, this may be the case for example for participants allocated to a cyberbullying role involving antisocial behavior (e.g., necessitating measures fostering prosocial behavior) in contrast to participants allocated to the cyberbullying role of "outsiders" (e.g., necessitating measures to motivate participants to intervene or measures to foster empathy). Future studies will have to shed light on this issue as well as replicate our present findings.

\section{Authors' Note}

During the study and the first steps of the present analyses the first and second authors were affiliated with Freie Universität Berlin, during the final steps and the textualisation of the results the first author was already affiliated with Technische Universität Berlin and the second author was affiliated with the German University of Health \& Sports.

\section{Acknowledgement}

This research was supported by a research grant from the DAPHNE III program to combat violence against children, young persons and women of the European Commission (Action Number: JLS/2008/DAP3/AG/1211-30CE-0311025/00-69; project title "Cyberbullying in Adolescence: Investigation and Intervention in Six European Countries" granted to the University of Bologna, Italy). The views expressed in this article are ours and do not represent the granting agency.

\section{References}

Anderson, C. A., \& Bushman, B. J. (2002). Human aggression. Annual Review of Psychology, 53, 27-51. https://doi.org/10.1146/annurev.psych.53.100901.135231

Ang, R. P., Huan, V. S., \& Florell, D. (2014). Understanding the relationship between proactive and reactive aggression, and cyberbullying across United States and Singapore adolescent samples. Journal of Interpersonal Violence, 29, 237-254. https://doi.org/10.1177/0886260513505149 
Barlett, C., \& Coyne, S. M. (2014). A meta-analysis of sex differences in cyber-bullying behavior: The moderating role of age. Aggressive Behavior, 40, 474-488. https://doi.org/10.1002/ab.21555

Barlińska, J., Szuster, A., \& Winiewski, M. (2013). Cyberbullying among adolescent bystanders: Role of the communication medium, form of violence, and empathy. Journal of Community \& Applied Social Psychology, 23, 3751. https://doi.org/10.1002/casp.2137

Barlińska, J., Szuster, A., \& Winiewski, M. (2015). The role of short- and long-term cognitive empathy activation in preventing cyberbystander reinforcing cyberbullying behavior. Cyberpsychology, Behavior, and Social Networking, 18, 241-244. https://doi.org/10.1089/cyber.2014.0412

Bastiaensens, S., Vandebosch, H., Poels, K., Van Cleemput, K., DeSmet, A., \& De Bourdeaudhuij, I. (2014). Cyberbullying on social network sites. An experimental study into bystanders' behavioural intentions to help the victim or reinforce the bully. Computers in Human Behavior, 31, 259-271.

https://dx.doi.org/10.1016/j.chb.2013.10.036

Batson, C. D. (2009). These things called empathy: Eight related but distinct phenomena. In J. Decety, \& W. Ickes (Eds.), The social neuroscience of empathy (pp. 3-15). Cambridge, MA, US: MIT Press.

Campbell, M. A., Whiteford, C., Duncanson, K., Spears, B., Butler, D., \& Slee, P. T. (2017). Cyberbullying bystanders: Gender, grade, and actions among primary and secondary school students in Australia. International Journal of Technoethics, 8(1), 44-55. https://doi.org/10.4018/JJT.2017010104

Collins, L. M. \& Lanza, S. T. (2010). Latent class and latent transition analysis: With applications in the social, behavioral, and health sciences. New York, NY: John Wiley.

Cook, C. R., Williams, K. R., Guerra, N. G., Kim, T. E., \& Sadek, S. (2010). Predictors of bullying and victimization in childhood and adolescence: A meta-analytic investigation. School Psychology Quarterly, 25, 65-83.

http://dx.doi.org/10.1037/a0020149

Craig, W. M., Pepler, D., \& Atlas, R. (2000). Observations of bullying in the playground and in the classroom. School Psychology International, 21, 22-36. https://doi.org/10.1177/0143034300211002

Crick, N. R., \& Dodge, K. A. (1996). Social information-processing mechanisms in reactive and proactive aggression. Child Development, 67, 993-1002. https://doi.org/10.2307/1131875

Davis, M. H. (1980). A multidimensional approach to individual differences in empathy. JSAS Catalog of Selected Documents in Psychology, 10, 85.

Davis, M. H. (1994). Empathy: A social psychological approach. Boulder, CO, US: Westview Press.

Del Rey, R., Casas, J. A., Ortega-Ruiz, R., Schultze-Krumbholz, A., Scheithauer, H., Smith, P., .. Plichta, P. (2015). Structural validation and cross-cultural robustness of the European Cyberbullying Intervention Project Questionnaire. Computers in Human Behavior, 50, 141-147. https://doi.org/10.1016/j.chb.2015.03.065

Del Rey, R., Lazuras, L., Casas, J. A., Barkoukis, V., Ortega-Ruiz, R., \& Tsorbatzoudis, H. (2016). Does empathy predict (cyber) bullying perpetration, and how do age, gender and nationality affect this relationship? Learning and Individual Differences, 45, 275-281. https://doi.org/10.1016/j.lindif.2015.11.021

DeSmet, A., Veldeman, C., Poels, K., Bastiaensens, S., Van Cleemput, K., Vandebosch, H., \& De Bourdeaudhuij, I. (2014). Determinants of self-reported bystander behavior in cyberbullying incidents amongst adolescents. Cyberpsychology, Behavior, and Social Networking, 17, 207-215. https://doi.org/10.1089/cyber.2013.0027 
DiFranzo, D., Taylor, S. H., Kazerooni, F., Wherry, O. D., \& Bazarova, N. N. (2018). Upstanding by design: Bystander intervention in cyberbullying. In Proceedings of the $2018 \mathrm{CHI}$ Conference on Human Factors in Computing Systems (paper 211). New York, NY: ACM.

Eisenberg, N., \& Miller, P. A. (1987). The relation of empathy to prosocial and related behaviors. Psychological Bulletin, 101, 91-119. https://doi.org/10.1037/0033-2909.101.1.91

Erikson, E. H. (1968). Identity: youth and crisis. Oxford, England: Norton \& Co.

Evans, C., \& Smokowski, P. (2015). Prosocial bystander behavior in bullying dynamics: Assessing the impact of social capital. Journal of Youth \& Adolescence, 44, 2289-2307. https://doi.org/10.1007/s10964-015-0338-5

Evers, K. E., Prochaska, J. O., Van Marter, D. F., Johnson, J. L., \& Prochaska, J. M. (2007). Transtheoretical-based bullying prevention effectiveness trials in middle schools and high schools. Educational Research, 49, 397-414. https://doi.org/10.1080/00131880701717271

Fend, H., Helmke, A., \& Richter, P. (1984). Inventar zu Selbstkonzept und Selbstvertrauen [Inventory for self-concept and self-confidence]. Konstanz: Universität Konstanz, Sozialwissenschaftliche Fakultät.

Gibbons, F. X., Gerrard, M., Blanton, H., \& Russell, D. W. (1998). Reasoned action and social reaction: Willingness and intention as independent predictors of health risk. Journal of Personality and Social Psychology, 74, 1164-1180. https://doi.org/10.1037/0022-3514.74.5.1164

Gini, G., Albiero, P., Benelli, B., \& Altoè, G. (2007). Does empathy predict adolescents' bullying and defending behavior? Aggressive Behavior, 33, 467-476. https://doi.org/10.1002/ab.20204

Gollwitzer, M. (2007). Latent-Class-Analysis. In H. Moosbrugger \& A. Kelava (Eds.), Testtheorie und Fragebogenkonstruktion [Test theory and questionnaire construction] (pp. 279-306). Heidelberg: Springer.

Gradinger, P., Strohmeier, D., \& Spiel, C. (2009). Traditional bullying and cyberbullying: Identification of risk groups for adjustment problems. Zeitschrift für Psychologie, 217, 205-213. https://doi.org/10.1027/00443409.217.4.205

Guo, S. (2016). A meta-analysis of the predictors of cyberbullying perpetration and victimization. Psychology in the Schools, 53, 432-453. https://doi.org/10.1002/pits.21914

Hoffman, M. L. (2000). Empathy and moral development: Implications for caring and justice. New York, NY US: Cambridge University Press.

Hoijtink, H. (2001). Confirmatory Latent Class Analysis: Model selection using Bayes factors and (pseudo) likelihood ratio statistics. Multivariate Behavioral Research, 36, 563-588.

http://dx.doi.org/10.1207/S15327906MBR3604_04

Hollá, K., Fenyvesiová, L., \& Hanuliaková, J. (2017). Measurement of Cyber-bullying severity. The New Educational Review, 47, 29-38.

Jenkins, L. N., \& Nickerson, A. B. (2017). Bullying participant roles and gender as predictors of bystander intervention. Aggressive Behavior, 43, 281-290. https://doi.org/10.1002/ab.21688

Kabert, S. (2011). A mixed-methods analysis of the effect of self-esteem on bullying frequency, bullying behaviors, and motivations to bully in adolescence (Doctoral dissertation). Retrieved from http://search.ebscohost.com/login.aspx?direct=true\&db=psyh\&AN=2011-99120-162\&site=ehost-live 
Kowalski, R. M., Guimetti, G. W., Schroeder, A. N., \& Lattanner, M. R. (2014). Bullying in the digital age: A critical review and meta-analysis of cyberbullying research among youth. Psychological Bulletin, 140, 1073-1137. https://doi.org/10.1037/a0035618

Kowalski, R. M., \& Limber, S. P. (2013). Psychological, physical, and academic correlates of cyberbullying and traditional bullying. Journal of Adolescent Health, 53, S13-S20. https://doi.org/10.1016/j.jadohealth.2012.09.018

Lamsfuss, S. M., Silbereisen, R. K., \& Boehnke, K. (1992). Empathie und Motive sozialen Handelns [Empathy and motives of social actions] (2nd ed.). Berlin: Arbeitsbereich Empirische Erziehungswissenschaft, Freie Universität Berlin.

Langos, C. (2012). Cyberbullying: The challenge to define. Cyberpsychology, Behavior, and Social Networking, 15, 285-289. https://doi.org/10.1089/cyber.2011.0588

Latané, B., \& Darley, J. M. (1970). The unresponsive bystander: Why doesn't he help? Englewood Cliffs, NJ: Prentice Hall.

Leduc, K., Conway, L., Gomez-Garibello, C., \& Talwar, V. (2018). The influence of participant role, gender, and age in elementary and high-school children's moral justifications of cyberbullying behaviors. Computers in Human Behavior, 83, 215-220. https://doi.org/10.1016/j.chb.2018.01.044

Lenhart, A., Madden, M., Smith, A., Purcell, K., Zickuhr, K., \& Rainie, L. (2011). Teens, kindness and cruelty on social network sites: How American teens navigate the new world of "digital citizenship". Washington, DC, US: Pew Research Center's Internet \& American Life Project. Retrieved from

http://search.ebscohost.com/login.aspx?direct=true\&db=eric\&AN=ED537516\&site=ehost-live

Little, T. D., Jones, S. M., Henrich, C. C., \& Hawley, P. H. (2003). Disentangling the "whys" from the "whats" of aggressive behaviour. International Journal of Behavioral Development, 27, 122-133.

https://doi.org/10.1080/01650250244000128

Macháčková, H., Dedkova, L., Sevcikova, A., \& Cerna, A. (2013). Bystanders' support of cyberbullied schoolmates. Journal of Community \& Applied Social Psychology, 23, 25-36. https://doi.org/10.1002/casp.2135

Macháčková, H., Dedkova, L., Sevcikova, A., \& Cerna, A. (2018). Bystanders' supportive and passive responses to cyberaggression. Journal of School Violence, 17, 99-110. https://doi.org/10.1080/15388220.2016.1222499

Macháčková, H., \& Pfetsch, J. (2016). Bystanders' responses to offline bullying and cyberbullying: The role of empathy and normative beliefs about aggression. Scandinavian Journal of Psychology, 57, 169-176.

https://doi.org/10.1111/sjop.12277

Mitsopoulou, E., \& Giovazolias, T. (2015). Personality traits, empathy and bullying behavior: A meta-analytic approach. Aggression and Violent Behavior, 21, 61-72. https://doi.org/10.1016/j.avb.2015.01.007

Muthén, L. K., \& Muthén, B. O. (1998-2012). Mplus user's guide (7th ed.). Los Angeles, CA, USA: Muthén \& Muthén.

Nickerson, A. B., Aloe, A. M., \& Werth, J. M. (2015). The relation of empathy and defending in bullying: A metaanalytic investigation. School Psychology Review, 44, 372-390. https://doi.org/10.17105/spr-15-0035.1

Nickerson, A. B., Mele, D., \& Princiotta, D. (2008). Attachment and empathy as predictors of roles as defenders or outsiders in bullying interactions. Journal of School Psychology, 46, 687-703.

https://doi.org/10.1016/j.jsp.2008.06.002

Norwood, F. B., \& Lusk, J. L. (2011). Social desirability bias in real, hypothetical, and inferred valuation experiments. American Journal of Agricultural Economics, 93, 528-534. https://doi.org/10.1093/ajae/aaq142 
Nylund, K. L., Asparouhov, T., \& Muthén, B. O. (2007). Deciding on the number of classes in latent class analysis and growth mixture modeling: A Monte Carlo simulation study. Structural Equation Modeling: A Multidisciplinary Journal, 14, 535-569. https://doi.org/10.1080/10705510701575396

Nylund, K., Bellmore, A., Nishina, A., \& Graham, S. (2007). Subtypes, severity, and structural stability of peer victimization: What does latent class analysis say? Child Development, 78, 1706-1722.

https://doi.org/10.1111/j.1467-8624.2007.01097.x

O'Moore, M., \& Kirkham, C. (2001). Self-esteem and its relationship to bullying behaviour. Aggressive Behavior, 27, 269-283. https://doi.org/10.1002/ab.1010

Olenik-Shemesh, D., Heiman, T., \& Eden, S. (2017). Bystanders' behavior in cyberbullying episodes: Active and passive patterns in the context of personal-socio-emotional factors. Journal of Interpersonal Violence, 32, 23-48. https://doi.org/10.1177/0886260515585531

Ortega, R., Elipe, P., Mora-Merchán, J. A., Calmaestra, J., \& Vega, E. (2009). The emotional impact on victims of traditional bullying and cyberbullying: A study of Spanish adolescents. Zeitschrift für Psychologie, 217, 197-204. https://doi.org/10.1027/0044-3409.217.4.197

Pabian, S., Vandebosch, H., Poels, K., Van Cleemput, K., \& Bastiaensens, S. (2016). Exposure to cyberbullying as a bystander: An investigation of desensitization effects among early adolescents. Computers in Human Behavior, 62, 480-487. https://doi.org/10.1016/j.chb.2016.04.022

Paciello, M. , Fida, R. , Tramontano, C. , Lupinetti, C. and Caprara, G. V. (2008). Stability and change of moral disengagement and its impact on aggression and violence in late adolescence. Child Development, 79, 1288-1309. https://doi.org/10.1111/j.1467-8624.2008.01189.x

Palladino, B. E., Menesini, E., Nocentini, A., Luik, P., Naruskov, K., Ucanok, Z., . . Scheithauer, H. (2017). Perceived severity of cyberbullying: Differences and similarities across four countries. Frontiers in Psychology, 8, article 1524. https://doi.org/10.3389/fpsyg.2017.01524

Paluck, E. L., \& Shepherd, H. (2012). The salience of social referents: A field experiment on collective norms and harassment behavior in a school social network. Journal of Personality and Social Psychology, 103, 899-915. https://doi.org/10.1037/a0030015

Patchin, J. W., \& Hinduja, S. (2010). Cyberbullying and self-esteem. Journal of School Health, 80, 614-621. https://doi.org/10.1111/j.1746-1561.2010.00548.x

Paulhus, D. L. (1984). Two-component models of socially desirable responding. Journal of Personality and Social Psychology, 46, 598-609. https://doi.org/10.1037/0022-3514.46.3.598

Pfetsch, J. (2016). Who is who in cyberbullying? Conceptual and empirical perspectives on bystanders in cyberbullying. In M. F. Wright (Ed.), A social-ecological approach to cyberbullying (pp. 121-150). Hauppauge, NY: Nova Science Publishers.

Pfetsch, J., Müller, C. R., \& Ittel, A. (2014). Cyberbullying und Empathie: Affektive, kognitive und medienbasierte Empathie im Kontext von Cyberbullying im Kindes- und Jugendalter [Cyberbullying and empathy: Affective, cognitive and media-based empathy in the context of cyberbullying in childhood and adolescence]. Diskurs Kindheits- und Jugendforschung, 9, 23-37. https://doi.org/10.3224/diskurs.v9i1.19081

Pfetsch, J., Müller, C. R., Walk, S., \& Ittel, A. (2014). Bewältigung von Cyberviktimisierung im Jugendalter Emotionale und verhaltensbezogene Reaktionen auf Cyberbullying [Coping with cybervictimization in adolescence - Emotional and behavioral reactions to cyberbullying]. Praxis der Kinderpsychologie und Kinderpsychiatrie, 63, 343-360. https://doi.org/10.13109/prkk.2014.63.5.343 
Quirk, R., \& Campbell, M. (2015). On standby? A comparison of online and offline witnesses to bullying and their bystander behaviour. Educational Psychology, 35, 430-448. https://doi.org/10.1080/01443410.2014.893556

Renati, R., Berrone, C., \& Zanetti, M. A. (2012). Morally disengaged and unempathic: Do cyberbullies fit these definitions? An exploratory study. Cyberpsychology, Behavior, and Social Networking, 15, 391-398. https://doi.org/10.1089/cyber.2012.0046

Rigby, K., \& Johnson, B. (2006). Expressed readiness of Australian schoolchildren to act as bystanders in support of children who are being bullied. Educational Psychology, 26, 425-440.

https://doi.org/10.1080/01443410500342047

Rosenberg, M. (1965). Society and the adolescent self-image. Princeton, NJ: University Press.

Salmivalli, C., Kaukiainen, A., Kaistaniemi, L., \& Lagerspetz, K. M. J. (1999). Self-evaluated self-esteem, peerevaluated self-esteem, and defensive egotism as predictors of adolescents' participation in bullying situations. Personality and Social Psychology Bulletin, 25, 1268-1278. https://doi.org/10.1177/0146167299258008

Salmivalli, C., Lagerspetz, K. M. J., Björkqvist, K., Österman, K., \& Kaukiainen, A. (1996). Bullying as a group process: Participant roles and their relations to social status within the group. Aggressive Behavior, 22, 1-15. https://doi.org/10.1002/(SICI)1098-2337(1996)22:1<1::AID-AB1>3.0.CO;2-T

Schultze-Krumbholz, A., Göbel, K., Scheithauer, H., Brighi, A., Guarini, A., Tsorbatzoudis, H., .. Smith, P. K. (2014). A comparison of classification approaches for cyberbullying and traditional bullying using data from six European countries. Journal of School Violence, 14, 47-65. https://doi.org/10.1080/15388220.2014.961067

Schultze-Krumbholz, A., Siebenbrock, A., Zagorscak, P., \& Scheithauer, H. (2011). MEDIENHELDEN Schülerfragebogen [MEDIA HEROES - Student questionnaire]. Unpublished questionnaire. Berlin: Freie Universität Berlin.

Schultze-Krumbholz, A., Zagorscak, P., Siebenbrock, A., \& Scheithauer, H. (2012). Medienhelden Unterrichtsmanual zur Förderung von Medienkompetenz und Prävention von Cybermobbing [Teaching manual for the promotion of media literacy and the prevention of cyberbullying]. München: Reinhardt Verlag.

Schultze-Krumbholz, A., Zagorscak, P., Wölfer, R., \& Scheithauer, H. (2014). Prävention von Cybermobbing und Reduzierung aggressiven Verhaltens Jugendlicher durch das Programm Medienhelden: Ergebnisse einer Evaluationsstudie [Prevention of cyberbullying and reduction of adolescents' aggressive behavior using the 'Medienhelden' program: Results from an evaluation study]. Diskurs Kindheits- und Jugendforschung, 2014(1), 6179. https://doi.org/10.3224/diskurs.v9i1.19083

Seals, D., \& Young, J. (2003). Bullying and victimization: Prevalence and relationship to gender, grade level, ethnicity, self-esteem, and depression. Adolescence, 38, 735-747.

Steffgen, G., König, A., Pfetsch, J., \& Melzer, A. (2011). Are cyberbullies less empathic? Adolescents' cyberbullying behavior and empathic responsiveness. Cyberpsychology, Behavior, and Social Networking, 14, 643-648. https://doi.org/10.1089/cyber.2010.0445

Sun, S., Fan, X., \& Du, J. (2016). Cyberbullying perpetration: A meta-analysis of gender differences. International Journal of Internet Science, 11, 61-81.

Sutton, J., Smith, P. K., \& Swettenham, J. (1999). Social cognition and bullying: Social inadequacy or skilled manipulation? British Journal of Developmental Psychology, 17, 435-450. https://doi.org/10.1348/026151099165384

Tarrant, M., MacKenzie, L., \& Hewitt, L. A. (2006). Friendship group identification, multidimensional self-concept, and experience of developmental tasks in adolescence. Journal of Adolescence, 29, 627-640.

https://doi.org/10.1016/j.adolescence.2005.08.012 
Tein, J., Coxe, S., \& Cham, H. (2013). Statistical Power to Detect the Correct Number of Classes in Latent Profile Analysis. Structural Equation Modeling: A Multidisciplinary Journal, 20, 640-657.

https://doi.org/10.1080/10705511.2013.824781

Tofighi, D., \& Enders, C. K. (2007). Identifying the correct number of classes in a growth mixture model. In G. R. Hancock, \& K. M. Samuelsen (Eds.), Advances in latent variable mixture models (pp. 317-341). Greenwich, CT: Information Age Publishing, Inc.

Tokunaga, R. S. (2010). Following you home from school: A critical review and synthesis of research on cyberbullying victimization. Computers in Human Behavior, 26, 277-287. https://doi.org/10.1016/j.chb.2009.11.014

Van Cleemput, K., Vandebosch, H., \& Pabian, S. (2014). Personal characteristics and contextual factors that determine 'helping,' 'joining in,' and 'doing nothing' when witnessing cyberbullying. Aggressive Behavior, 40, 383396. https://doi.org/10.1002/ab.21534

Van der Graaff, J., Branje, S., De Wied, M., Hawk, S., Van Lier, P., \& Meeus, W. (2014). Perspective taking and empathic concern in adolescence: Gender differences in developmental changes. Developmental Psychology, 50, 881-888. https://doi.org/10.1037/a0034325

van Noorden, T. H. J., Haselager, G. J. T., Cillessen, A. H. N., \& Bukowski, W. M. (2015). Empathy and involvement in bullying in children and adolescents: A systematic review. Journal of Youth and Adolescence, 44, 637-657.

https://doi.org/10.1007/s10964-014-0135-6

Volland, C., Ulich, D., Kienbaum, J., \& Hölzle, E. (2008). Doing gender by doing emotion? Die geschlechtsspezifische Entwicklung der Mitgefühlsbereitschaft im Jugendalter [Doing gender by doing emotion? The gender-specific development of readiness for sympathy in adolescence]. Psychologie in Erziehung und Unterricht, 55, 27-38.

Werth, L. \& Mayer, J. (2008). Sozialpsychologie [Social psychology]. Heidelberg: Springer.

Williams, K. R., \& Guerra, N. G. (2007). Prevalence and predictors of internet bullying. Journal of Adolescent Health, 41, S14-S21. https://doi.org/10.1016/j.jadohealth.2007.08.018

Zurek, P. P., \& Scheithauer, H. (2017). Towards a more precise conceptualization of empathy: An integrative review of literature on definitions, associated functions, and developmental trajectories. International Journal of Developmental Science, 11, 57-68. https://doi.org/10.3233/DEV-16224

\section{Correspondence to:}

Anja Schultze-Krumbholz

Institute of Education, Department of Educational Psychology

Technische Universität Berlin

Marchstr. 23, MAR 2-6

10587 Berlin

Germany

Email: anja.schultze-krumbholz(at)tu-berlin.de

Editorial record: First submission received on April 30, 2018. Revisions received on July 30, 2018 and November 11, 2018. Accepted for publication on November 19, 2018.

The article is part of the Special Issue "Bystanders of Online Aggression" guest edited by Hana Machackova (Masaryk University, Brno, Czechia), Jan Pfetsch (Technische Universität, Berlin, Germany), and Georges Steffgen (University of Luxembourg, Luxembourg). 


\section{About Authors}

Anja Schultze-Krumbholz, Dr., is a post-doctoral researcher at the Department of Educational Psychology at Technische Universität Berlin, Germany. She previously worked at Freie Universität Berlin and is first author of the German cyberbullying prevention program "Medienhelden" ("Media Heroes"). Her dissertation focused on cyberbullying (nature, prevalence, impact and prevention). Her current research interests are bullying and cyberbullying, aggression in childhood and adolescence, social-emotional development, classroom influences on behavior, and discrimination and ethnic bullying.

Markus Hess, Dr., received his Degree in Psychology (Diploma) in 2001 from University of Würzburg, Germany, and his Ph.D. in 2013 from the University of Potsdam, Germany. He currently holds a professorship for Applied Psychology with a focus on Social and Developmental Psychology at the German University of Health \& Sports in Berlin, Germany. He previously worked at Freie Universität Berlin, Germany. His research interests focus on violence prevention, the development of social-emotional competencies in different contexts (peers, family) and age-groups, and (cyber-)bullying.

Jan Pfetsch, Dr., is guest professor and deputy head of the Department of Educational Psychology at Technische Universität Berlin, Germany. He developed a bystander intervention training in the context of offline bullying at school. His current research focuses on cyberbullying (especially cyberbystanders), empathy in offline and online contexts, media use and media literacy, development of competencies in teacher training (esp. diagnostic competence), learning with digital media, and aggressive and prosocial behavior in children and adolescents.

Herbert Scheithauer, Dr., is Professor for Developmental and Clinical Psychology and head of the Division of Developmental Science and Applied Developmental Psychology at Freie Universität Berlin, Germany. He is a member of several national, European and international advisory boards and scientific networks. He has experience in the development, evaluation, and implementation of violence prevention programs, e.g. Papilio, Fairplayer.Manual, NETWASS, Medienhelden, Fairplayer.Sport. He is Editor-in-Chief of the International Journal of Developmental Science. 